\title{
PLASIM-GENIE v1.0: a new intermediate complexity AOGCM
}

\author{
Philip B. Holden ${ }^{1}$, Neil R. Edwards ${ }^{1}$, Klaus Fraedrich ${ }^{2}$, Edilbert Kirk ${ }^{3}$, Frank Lunkeit ${ }^{3}$, and Xiuhua Zhu ${ }^{4}$ \\ ${ }^{1}$ Environment, Earth and Ecosystems, The Open University, Walton Hall, Milton Keynes, MK7 6AA, UK \\ ${ }^{2}$ Max Planck Institute of Meteorology, KlimaCampus, Bundesstraße 53, 20146 Hamburg, Germany \\ ${ }^{3}$ Meteorological Institute, University of Hamburg, Bundesstraße 55, 20146 Hamburg, Germany \\ ${ }^{4}$ Center for Earth System Research and Sustainability (CEN), University of Hamburg, Grindelberg 5, \\ 20144 Hamburg, Germany
}

Correspondence to: Philip B. Holden (p.b.holden@open.ac.uk)

Received: 18 November 2015 - Published in Geosci. Model Dev. Discuss.: 18 December 2015

Revised: 9 May 2016 - Accepted: 25 May 2016 - Published: 21 September 2016

\begin{abstract}
We describe the development, tuning and climate of Planet Simulator (PLASIM)-Grid-ENabled Integrated Earth system model (GENIE), a new intermediate complexity Atmosphere-Ocean General Circulation Model (AOGCM), built by coupling the Planet Simulator to the ocean, sea-ice and land-surface components of the GENIE Earth system model. PLASIM-GENIE supersedes GENIE2, a coupling of GENIE to the Reading Intermediate General Circulation Model (IGCM). The primitive-equation atmosphere includes chaotic, three-dimensional (3-D) motion and interactive radiation and clouds, and dominates the computational load compared to the relatively simpler frictionalgeostrophic ocean, which neglects momentum advection. The model is most appropriate for long-timescale or large ensemble studies where numerical efficiency is prioritised, but lack of data necessitates an internally consistent, coupled calculation of both oceanic and atmospheric fields. A 1000-year simulation with PLASIM-GENIE requires approximately 2 weeks on a single node of a $2.1 \mathrm{GHz}$ AMD $6172 \mathrm{CPU}$. We demonstrate the tractability of PLASIM-GENIE ensembles by deriving a subjective tuning of the model with a 50member ensemble of 1000-year simulations. The simulated climate is presented considering (i) global fields of seasonal surface air temperature, precipitation, wind, solar and thermal radiation, with comparisons to reanalysis data; (ii) vegetation carbon, soil moisture and aridity index; and (iii) sea surface temperature, salinity and ocean circulation. Considering its resolution, PLASIM-GENIE reproduces the main features of the climate system well and demonstrates usefulness for a wide range of applications.
\end{abstract}

\section{Introduction}

The Grid-ENabled Integrated Earth system model (GENIE; Lenton et al., 2007) has been developed as a modular framework that allows for a spectrum of intermediate complexity Earth system models to be created by selecting different options for the various climate and carbon cycle components. Earth system models created within GENIE have been configured for published studies spanning a wide range of geological epochs across Paleozoic, Mesozoic and Cenozoic eras. GENIE framework models are normally capable of integration over multi-millennial timescales and several of the published studies have involved millions of years of simulation time, combining long runs and large ensembles. The framework has been designed to be modular to facilitate the coupling of more complex component modules as available computing power increases.

Almost invariably, applications of GENIE have used configurations that represent the atmosphere with a computationally fast energy-moisture-balance model (EMBM; Fanning and Weaver, 1996). These configurations are generically named GENIE-1. Although adequate for many purposes, especially in the context of global biogeochemical modelling, an EMBM introduces significant structural weaknesses to (or even rules out) a range of applications. Diffusive single-layer moisture transport leads to poor precipitation fields that cannot, for instance, represent convective precipitation or monsoon dynamics. The EMBM applies prescribed surface wind fields (Edwards and Marsh, 2005), defined either from climatology or from outputs of more complex models, so that dynamic ocean feedbacks are restricted to the thermohaline cir- 
culation. Clouds are represented through a prescribed albedo field (Lenton et al., 2006) and a spatially uniform adjustment to outgoing longwave radiation (OLR; Holden et al., 2010), while uncertain cloud feedbacks on the radiative balance in a changing climate are represented through a globally uniform temperature-dependent adjustment to OLR (Matthews and Caldeira, 2007; Holden et al., 2010).

In an effort to address these shortcomings, the Reading Intermediate General Circulation Model (IGCM3.1; de Forster et al., 2000), a three-dimensional (3-D) dynamical model of the atmosphere, was coupled into GENIE (Annan et al., 2005; Lenton et al., 2007). Unfortunately, GENIE-2 proved problematic and has only been applied once since these early studies (Holden and Edwards, 2010). The coupling with the slab-ocean model was found to exhibit poor precipitation fields, apparently due to structural deficiencies in the convection routine (Annan et al., 2005). The coupling with the 3-D frictional-geostrophic ocean model GOLDSTEIN displays a patchwork instability and exhibits a low bias in precipitation over the ocean. GENIE-2 requires a large moisture flux correction $(0.79 \mathrm{~Sv}$, reversing the sign of the simulated flux) to reconcile freshwater transport from the Atlantic to the Pacific with reanalysis data (Lenton et al., 2007) and generate an Atlantic overturning circulation. A further shortcoming is that, on account of technical complications discussed in Sect. 3.3, the IGCM was not coupled to the dynamic sea-ice module GOLDSTEINSEAICE, but only to the slab sea-ice module ${ }^{1}$.

GENIE-1 has been applied to a wide range of studies, including participation in the Earth System Models of Intermediate Complexity (EMIC) inter-comparisons that were performed for the two most recent IPCC reports (Plattner et al., 2008; Zickfeld et al., 2013). Although GENIE studies have generally addressed ocean physics, ocean biogeochemistry and the global carbon cycle, a more recent focus has been the development of emulators for climate impact assessment (e.g. Labriet et al., 2015; Mercure et al., 2014). This application is poorly suited to highly simplified atmospheric models such as the EMBM. Although the emulation techniques were developed from GENIE-2 simulations (Holden and Edwards, 2010), this first-generation emulator was not considered sufficiently robust for applications given the poor climatology of the underlying simulator. Instead, a second-generation emulator (Holden et al., 2014) was developed using the Planet Simulator (PLASIM; Fraedrich, 2012).

PLASIM is a reduced complexity Atmosphere General Circulation Model (AGCM), with the 3-D primitive-equation Portable University Model of the Atmosphere (PUMA) at its core (Fraedrich et al., 2005). We use the PLASIM-ENTS (ef-

\footnotetext{
${ }^{1}$ The GENIE slab sea-ice module assumes a fixed thickness $(2 \mathrm{~m})$, heat capacity and albedo (0.6). A grid cell becomes completely ice covered when the surface temperature falls below $-2{ }^{\circ} \mathrm{C}$, with surface temperature evolving according to the energy flux balance. Sea-ice dynamics are neglected and there is no interaction with the hydrological cycle.
}

ficient numerical terrestrial scheme) implementation (Holden et al., 2014), which incorporates the same land surface model as GENIE. Complementary to GENIE-1, PLASIM has been applied in a range of atmospheric studies, for instance investigating the global entropy budget (Fraedrich and Lunkeit, 2008), double Inter-Tropical Convergence Zone dynamics in an aquaplanet (Dahms et al., 2011), the Permian climate (Roscher et al., 2011) and a snowball Earth (Micheels and Montenari, 2008). However, although PLASIM simulates vastly better climatology than the EMBM of GENIE-1, it lacks dynamic representations of ocean and sea ice (and does not model the carbon cycle), so it too neglects important Earth system feedbacks.

Here we describe the implementation of a coupling of PLASIM-ENTS to the physical components of the GENIE framework. The coupled model PLASIM-GENIE has been developed to join the limited number of models that bridge the gap between EMICs with simplified atmospheric dynamics and state of the art Atmosphere-Ocean General Climate Models (AOGCMs). We are aware of three AOGCMs of comparable complexity with primitive-equation atmospheric dynamics: FAMOUS (Fast Met Office/UK Universities Simulator), the reduced resolution implementation of the Hadley Centre Coupled Model (HadCM3), which simulates 1000 years in approximately 10 days on eight CPUs (Williams et al., 2013), SPEEDO (Speedy-Ocean), comprising a T30 spectral atmosphere with simplified parameterisations (Molteni, 2003) coupled to a primitive-equation ocean model, which simulates 1000 years in approximately 2 weeks on a $3 \mathrm{GHz}$ dual core Intel E6850 CPU (Severijns and Hazeleger, 2010) and OSUVic (Oregon State University Victoria), a coupling of PLASIM to the UVic Earth system model (Schmittner et al., 2010). A 1000-year simulation with PLASIM-GENIE requires approximately 2 weeks on a single node of a $2.1 \mathrm{GHz}$ AMD $6172 \mathrm{CPU}$.

State of the art climate models operate at the limit of available computing power, so that very few simulations can be performed with these models. An important motivation for intermediate complexity models is for the evaluation of uncertainty. We here demonstrate the tractability of PLASIMGENIE ensembles by tuning the model with a 50 -member ensemble of 1000-year simulations.

\section{Component modules}

\subsection{PLASIM-ENTS}

PLASIM (Fraedrich, 2012) is a reduced complexity AGCM, with the 3-D primitive-equation atmosphere model PUMA at its core (Fraedrich et al., 2005). PLASIM is described in detail in Lunkeit et al. (2007) and references therein. We summarise briefly here. The atmospheric dynamics are solved using the spectral transform method, formulated for temperature, specific humidity, log surface pressure, divergence and 
vorticity. The shortwave radiation scheme separates solar radiation into two bands, $\lambda<0.75 \mu \mathrm{m}$ (with cloud scattering, ozone absorption and Rayleigh scattering) and $\lambda>0.75 \mu \mathrm{m}$ (with cloud scattering, cloud absorption and water vapour absorption). The longwave radiation scheme uses the broadband emissivity method, with the (greenhouse gas) effect of water vapour, carbon dioxide and ozone included in the calculation of emissivity. Ozone concentration is prescribed with an analytic spatio-temporal distribution. Cloud emissivity is calculated from the cloud liquid water content. Fractional cloud cover is diagnosed from relative humidity (stratiform clouds) and from the convective precipitation rate (convective clouds). Other parameterised processes include largescale precipitation, moist convection (both cumulus and shallow), dry convection, boundary layer heat fluxes, vertical diffusion (to represent unresolved turbulent exchange) and horizontal diffusion (applied to selectively dampen short wavelengths in spectral space).

The land surface scheme (previously the Simulator for Biospheric Aspects, SimBA; Kleidon et al., 2005) was modified (Holden et al., 2014) to use GENIE's ENTS (Williamson et al., 2006), partly in anticipation of this coupling to GENIE. ENTS models vegetative and soil carbon densities, assuming a single plant functional type that has a doubled-peaked temperature response (representing boreal and tropical forest). In addition to temperature, the rate of photosynthesis depends upon the atmospheric $\mathrm{CO}_{2}$ concentration and on soil moisture availability. ENTS includes a parameterisation of self-shading, so that new photosynthetic production is channelled into leaf litter when fractional vegetation coverage approaches one and the canopy closes. Land surface albedo, moisture bucket capacity and surface roughness are parameterised in terms of the simulated carbon pool densities. We note that although the state variables simulated by ENTS are the vegetation and soil carbon densities, we have not coupled PLASIM-GENIE to the GENIE-1 carbon cycle; this extension is straightforward in principle and will be addressed in future work. In this coupling, ENTS can be run in a diagnostic mode (setting parameter nbiome at 2), simulating dynamically changing terrestrial carbon pools without affecting the climate state.

PLASIM includes flux-corrected slab-ocean and sea-ice models ${ }^{2}$. The coupling described here (Sect. 3) replaces these simple models with the 3-D dynamical ocean model GOLDSTEIN and the thermodynamic-dynamical sea-ice model GOLDSTEINSEAICE.

\subsection{GOLDSTEIN}

GOLDSTEIN is a 3-D frictional-geostrophic ocean model (Edwards and Marsh, 2005; Marsh et al., 2011). GOLD-

\footnotetext{
${ }^{2}$ The PLASIM sea-ice model is based on the thermodynamic model of Semtner (1976). It neglects dynamics. Spatio-temporal energy flux corrections are diagnosed from comparison with observed present-day sea-ice thickness.
}

STEIN is dynamically similar to classical GCMs (General Circulation Models), except that it neglects momentum advection and acceleration. Barotropic flow around Antarctica is derived from linear constraints that arise from integrating the depth-averaged momentum equations; we here neglect flow through other straits. Several modifications to the default GOLDSTEIN can be enabled; here we apply the modified equation of state that includes a density adjustment for thermobaricity given by $2.5 \times 10^{-5} T z \mathrm{~kg} \mathrm{~m}^{-3}$, where $T$ is temperature $\left({ }^{\circ} \mathrm{C}\right)$ and $z$ is height, i.e. negative depth (m), and the enhanced diapycnal mixing scheme (Oliver and Edwards, 2008).

\subsection{GOLDSTEINSEAICE}

GOLDSTEINSEAICE (Edwards and Marsh, 2005) solves for the fraction of the ocean surface covered by ice within a grid cell and for the average sea-ice height. A diagnostic equation is solved for the ice surface temperature. Growth or decay of sea ice depends on the net heat flux into the ice (Semtner, 1976; Hibler, 1979); sea-ice dynamics consists of advection by surface currents and diffusion. The thermodynamics of GOLDSTEINSEAICE are summarised in detail in Sect. 3.3.

\section{Coupling methodology}

A schematic of the PLASIM-ENTS-GOLDSTEINGOLDSTEINSEAICE "pl_go_gs" coupling is illustrated in Fig. 1.

In order to avoid the need for interpolation, the coupling was set up to so that the three models have matching horizontal grids. PLASIM has previously been configured for T21, T31 and T42 resolutions. Here we restrict the coupling to T21 and use the matched $64 \times 32$ GOLDSTEIN grid (Lenton et al., 2007). PLASIM vertical resolution is 10 levels. GOLDSTEIN depth resolution is 32 levels, with bathymetry defined at the resolution of the 8 level configuration. Extension to other resolutions (horizontal or vertical) is straightforward in principle.

The computational demands of the coupled model, simulating 75 years per day on a single node of a $256 \mathrm{~Gb} 2.1 \mathrm{GHz}$ AMD $6172 \mathrm{CPU}$, are dominated by PLASIM (98\%). The computational demands of PLASIM are dominated by diabatic processes $(\sim 76 \%)$, in particular by radiation $(\sim 43 \%)$ and precipitation $(\sim 16 \%)$. We note that the modular structure of PLASIM means that replacing the radiation scheme with, for example, a computationally fast semi-grey scheme (Frierson et al., 2006) would be relatively straightforward. An efficient convective adjustment scheme (Betts and Miller, 1986) is already available as an alternative to the default moisture budget scheme (Kuo, 1965, 1974). 


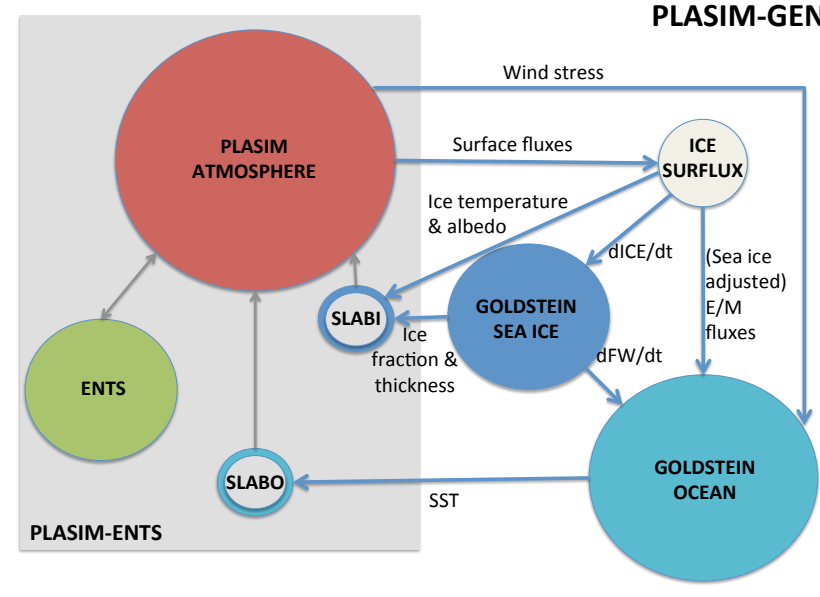

Figure 1. A schematic of the PLASIM-GENIE coupling. The circles represent the component modules, with sizes indicative of their relative complexity. The grey box defines the PLASIMENTS model, which has been retained in its entirety; hollow circles (SLABO and SLABI) are dummy PLASIM modules, retained only to specify ocean and sea-ice boundary conditions from GOLDSTEIN outputs; grey lines are energy and moisture fluxes that are calculated within the pre-existing PLASIM-ENTS coupling. Blue arrows are variables passed in the PLASIM-GENIE coupling. ICESURFLUX is the new surface flux routine that was developed for the coupling (see Sect. 3.3).

\subsection{PLASIM-ENTS}

The choice was made to preserve the coupled PLASIMENTS model in its entirety. The slab-ocean and sea-ice modules are retained only to provide boundary conditions; their state variables are over-written with GOLDSTEIN and GOLDSTEINSEAICE outputs, effectively negating the very simple dynamics of these models. This simplifies the coupling because the energy and moisture flux calculations are already made within PLASIM. The changes needed for PLASIM with this approach are therefore kept to a minimum, consisting of prescribing the slab ocean with GOLDSTEIN distributions of sea surface temperature and the slab seaice with GOLDSTEINSEAICE distributions of sea-ice fractional coverage, height, surface temperature and albedo. Furthermore, although GENIE contains a stand-alone version of the land surface module ENTS, the decision was taken to leave the existing PLASIM-ENTS coupling in place. Future work may separate the PLASIM and ENTS modules. The primary motivation for this would be modularity. Notably GENIEfied ENTS is coupled to the global carbon cycle (Lenton et al., 2006) and has been enabled to simulate the effects of anthropogenic land use change (Holden et al., 2013a).

\subsection{GOLDSTEIN}

No changes were made to GOLDSTEIN. Surface wind stress, net energy and net moisture fluxes are supplied from PLASIM, modified by sea ice where relevant. We note that we use a PLASIM time step of $45 \mathrm{~min}$ and a GOLDSTEIN time step of $12 \mathrm{~h}$, with coupling inputs averaged over the previous 16 PLASIM time steps (12 h).

\subsection{GOLDSTEINSEAICE}

In GENIE-1 the thermodynamics of GOLDSTEINSEAICE are calculated within the EMBM, and coupling to alternative model atmospheres is not possible with this model structure. To enable a PLASIM-GOLDSTEINSEAICE coupling, we have developed a stand-alone sea-ice thermodynamics routine.

Time-averaged incoming energy fluxes and atmospheric boundary conditions are supplied to the new ice surface flux (ICE-SURFLUX) routine from PLASIM. Sea surface temperature and salinity, sea-ice height and fractional sea-ice coverage are provided from the previous GOLDSTEIN/SEAICE time step.

ICE-SURFLUX closely follows the formulation of Edwards and Marsh (2005), where it is described in some detail. We summarise the approach here. Sea ice is assumed to have no heat capacity, so that the heat flux exchanged with the atmosphere equals the heat flux through the ice, thereby defining the vertical temperature gradient across the ice. The temperature at the sea-ice base is assumed equal to the salinitydependent freezing point of the surface ocean, so that the ice-surface temperature is the remaining unknown. Now we need to derive the net heat flux from the atmosphere. Incoming radiative fluxes are provided by PLASIM; outgoing radiative fluxes, and sensible and latent heat fluxes are dependent upon the surface temperature of the sea ice, together with atmospheric boundary conditions. These relationships together imply an ice-surface temperature (and the associated atmospheric heat flux) that balances the heat budget, which is solved for with a Newton-Raphson algorithm. The heat flux exchanged with the ocean is implied by the temperature differential between the sea-ice base (freezing point) and the surface ocean. The difference between the heat flux exchanged with the atmosphere and with the ocean is consumed by creating or melting ice.

The diagnosed energy and moisture fluxes are not passed to PLASIM. Instead, in order to achieve energy and moisture conservation, PLASIM transfer coefficients are used in the calculation of sensible heat and sublimation during the Newton-Raphson step. This ensures that net fluxes calculated in PLASIM (which use the sea-ice temperature and albedo derived in ICE-SURFLUX) will be consistent with those calculated in ICE-SURFLUX, but does not guarantee perfect conservation. Conservation errors arise through differential time stepping (the averaging of non- 
linear flux terms over 16 PLASIM time steps) and also because PLASIM does not explicitly account for sea-ice leads; ICE-SURFLUX separately accounts for ocean and sea-ice in a partially covered grid cell, but PLASIM fluxes are derived from weighted average surface properties ${ }^{3}$. To evaluate the magnitude of the conservation errors, we consider all of the sea-ice covered grid cells at each time step across a year of the spun-up model. The energy conservation error across these 152495 data points is $0.1 \pm 1.0 \mathrm{Wm}^{-2}(1 \sigma)$. We note that the PLASIM atmosphere does not precisely conserve energy, as illustrated by Hoskins and Simmons (1975) for a similar dry dynamical core. The largest effect in PLASIM comes from the conversion from potential to kinetic energy. This conversion cannot be formulated in a conservative manner in the semi-spectral scheme since it involves triple products while the (Gaussian) grid only allows for the conservation of quadratic quantities. The top-of-atmosphere energy balance converges to $-0.7 \mathrm{Wm}^{-2}$ in both the coupled and stand-alone versions of PLASIM, dominating over the conservation errors of ICE-SURFLUX.

Sea-ice growth rates are provided to GOLDSTEINSEAICE, which derives updated sea-ice distributions, considering both thermodynamics and dynamics (advection and diffusion). The updated sea-ice distribution is provided to PLASIM and the associated freshwater exchange with the ocean is provided to GOLDSTEIN.

\section{Tuning methodology}

Our approach for the selection of a tuned set of parameter values was to retain the existing tunings of models where possible (for exceptions see Sect. 4.1) and to only consider the parametric uncertainty of GOLDSTEIN. The motivation was that both PLASIM (Lunkeit et al., 2007) and ENTS (Williamson et al., 2006) have already been tuned to reproduce observations when forced with climatology 4 . In contrast, existing GOLDSTEIN tunings have been developed within a coupled atmosphere-ocean model, usually the EMBM atmosphere. We anticipated that a tuning of GOLDSTEIN that reproduces the main features of global ocean circulation when coupled to climatologically tuned PLASIMENTS would likely provide a good representation of observed climatology in general.

We performed a 50-member ensemble of 1000-year preindustrial spin-up simulations varying six GOLDSTEIN pa-

\footnotetext{
${ }^{3} \mathrm{~A}$ drift over the 2000-year spin-up simulation is apparent in the sixth significant figure of global-averaged salinity, likely also a consequence of the neglect of sea-ice leads in PLASIM and the differential time stepping. While this modest failure of moisture conservation is negligible for the physical model, it will be revisited for the carbon cycle coupling in order to ensure conservation of biogeochemical tracers.

${ }^{4}$ The diurnal cycle is switched off in these simulations, reflecting the default assumption for both the PLASIM and ENTS tunings.
}

rameters, in the expectation that some subset of ensemble members would produce reasonable climate states from which we could select a tuned model. (Failure in this regard would have necessitated the application of more sophisticated statistical techniques for searching parameter input space.)

\subsection{Ensemble design}

Parameters from modules other than GOLDSTEIN were all fixed. However, some were changed from their default values (or are recently introduced parameterisations that are not associated with tuned defaults). These choices were made on the basis of exploratory simulations:

i. The uncertain effect of clouds on longwave radiation is controlled through the dependence of cloud emissivity $A$ on the mass absorption factor $k$ "acllwr", following Slingo and Slingo (1991):

$A=1-e^{-\beta k W}$,

where $\beta=1.66$ is the diffusivity factor and $W$ the cloud liquid water path. The mass absorption factor was found to exert the strongest control on surface air temperature of the 22 key model parameters considered in PLASIMENTS ensembles (Holden et al., 2014). The value was increased from default $k=0.1$ to $0.2 \mathrm{~m}^{2} \mathrm{~g}^{-1}$, estimated to yield a simulated global average surface air temperature of approximately $14{ }^{\circ} \mathrm{C}$ in conjunction with parameter choices (ii) to (v) below.

ii. The PLASIM parameter albseamax defines the latitudinal variation of ocean albedo (Holden et al., 2014):

$\alpha_{\mathrm{s}}=\alpha_{\mathrm{s} 0}+0.5 \alpha_{\mathrm{s} 1}[1-\cos (2 \varphi)]$

where the ocean albedo $\alpha_{\mathrm{s}}$ is expressed in terms of latitude $\varphi$, the albedo at the Equator $\alpha_{\mathrm{s} 0}=0.069$ and the parameter that controls latitudinal variability $\alpha_{\mathrm{s} 1}$. The calculated albedo is applied to both direct and scattered radiation. A high value $\left(\alpha_{\mathrm{s} 1}=0.4\right)$ was favoured for albseamax, leading to cooler high latitude ocean and favouring increased Southern Ocean sea-ice and deepwater formation, which both tended to be too low with default parameters.

iii. Sea ice is transported through advection and Laplacian diffusion (Edwards and Marsh, 2005), the latter taking the place of a detailed representation of unresolved advection and rheological processes. Sea-ice diffusivity (SID) influences Antarctic Bottom Water (AABW) formation by controlling the rate at which new ice is created, and hence the strength of brine rejection (Holden et al., 2013b). A high value was favoured, again to strengthen deep-water formation, but values greater than $15000 \mathrm{~m}^{2} \mathrm{~s}^{-1}$ were found to lead to numerical instabilities in this model and SID was fixed at this value. 
iv. The standard PLASIM expression for the dependence of sea-ice albedo $\alpha_{i}$ on surface air temperature is used:

$\alpha_{\mathrm{i}}=0.5-0.025 T_{\mathrm{air}}$,

where $T_{\text {air }}$ is the surface air temperature $\left({ }^{\circ} \mathrm{C}\right)$. PLASIM restricts the maximum albedo to $0.7\left(T_{\text {air }} \leq-8^{\circ} \mathrm{C}\right)$. In PLASIM-GENIE we additionally restrict the minimum albedo to $0.5\left(T_{\text {air }} \geq 0{ }^{\circ} \mathrm{C}\right)$.

v. The PLASIM-ENTS dependency of photosynthesis on soil moisture is

$$
f_{2}\left(W_{\mathrm{s}}\right)=\left\{\left(W_{\mathrm{s}} / W_{\mathrm{s}}^{*}\right)-q_{\mathrm{th}}\right\} /\left\{0.75-q_{\mathrm{th}}\right\} .
$$

The parameter $q_{\text {th }}$ (qthresh) was set to 0.1 , allowing the development of vegetation in semi-arid regions (Holden et al., 2014).

The ensemble was generated using a $50 \times 6$ maximin latin hypercube design, varying six GOLDSTEIN parameters, listed in Table 1 and varied over ranges considered to reflect the plausible range for each parameter (Holden et al., 2013b, and references therein). The six varied parameters are isopycnal and diapycnal diffusivities, a parameter OP1 that controls the depth profile of diapycnal diffusivity (see below), ADRAG, the inverse frictional drag coefficient (GOLDSTEIN is based upon the thermocline equations with the addition of a linear drag term in the horizontal momentum equations; Edwards et al., 1998), wind-stress scaling (a linear scaling of the surface wind stress is applied to compensate for the energy dissipated by frictional drag) and an Atlantic-Pacific moisture flux adjustment.

Diapycnal diffusivity is stratification-dependent (Oliver and Edwards, 2008), given by

$k_{v}=k_{v 0} p_{0}(z)^{\gamma}\left(\frac{\Delta \rho_{0}(z)}{\Delta \rho(z)}\right)$,

where $k_{v 0}$ (reference diapycnal diffusivity) and $\gamma$ (OP1) are varied across the ensemble (Table 1$), p_{0}(z)$ is a reference profile (exponentially growing with depth and equal to 1 at $2500 \mathrm{~m}), \Delta \rho_{0}(z)$ a reference vertical density gradient profile and $\Delta \rho(z)$ the local simulated vertical density gradient.

The following two ensemble parameters merit particular discussion here.

\subsubsection{APM}

APM is a flux adjustment that transports moisture from the Atlantic to the Pacific, originally developed for the EMBM coupling (Edwards and Marsh, 2005). The default flux adjustment $(0.32 \mathrm{~Sv})$ is subdivided into three latitude bands reflecting the observed Atlantic-Pacific moisture transport (Oort, 1983): $-0.03 \mathrm{~Sv}$ south of $20^{\circ} \mathrm{S}, 0.17 \mathrm{~Sv}$ in the tropical zone $20^{\circ} \mathrm{S}$ to $24^{\circ} \mathrm{N}$ and $0.18 \mathrm{~Sv}$ north of $24^{\circ} \mathrm{N}$. Exploratory simulations suggested that PLASIM-GENIE would likely require a moisture flux adjustment and APM was introduced as an ensemble variable. APM is varied across ensemble members by a linear scaling preserving the ratio of fluxes between latitude bands.

An exploratory simulation with a flux adjustment of $0.32 \mathrm{~Sv}$ was performed and integrated net input freshwater fluxes (precipitation, evaporation, runoff and the flux adjustment) were diagnosed for the Arctic/Atlantic and the Pacific. In both basins, grid cells north of $32^{\circ} \mathrm{S}$ were included, following the observational estimates of Talley (2008). Values of $-0.5 \mathrm{~Sv}$ and $+0.1 \mathrm{~Sv}$ respectively, were diagnosed, compared to observations of $-0.28 \pm 0.04$ and $+0.04 \pm 0.09 \mathrm{~Sv}$ (Talley, 2008). Informed by this result, we allowed APM to vary in the range 0 to $0.32 \mathrm{~Sv}$.

PLASIM has also been coupled to the UVic Earth system model, creating the OSUVic model (Schmittner et al., 2010). The most significant difference between PLASIM-GENIE and USOVic is the differing complexity of the ocean models; USOVic incorporates the more complex primitive-equation Modular Ocean Model (MOM) version 2.2 (Pacanowski, $1995)$ at a horizontal resolution of $1.8^{\circ} \times 3.6^{\circ}$; the primitive equations include momentum advection terms neglected in our system. At T21 atmospheric resolution, the integrated Atlantic surface moisture balance simulated by OSUVic $(-0.33 \mathrm{~Sv})$ is in good agreement with observations without any flux adjustment. However, OSUVic nevertheless simulates a weak $(9 \mathrm{~Sv})$ Atlantic overturning circulation at T21 resolution. This was attributed in part to errors in the latitudinal distribution of the simulated moisture flux, which create low surface ocean salinities at high latitudes in the Atlantic (balanced by high salinity at low latitudes). We note that an exploratory PLASIM-GENIE simulation with a uniformly distributed 0.32 Sv moisture flux adjustment also exhibited low Atlantic salinity at high latitudes and weak overturning.

\subsubsection{SCF}

SCF scales the surface wind stresses that are applied to GOLDSTEIN. The scaling is needed because the frictionalgeostrophic ocean dissipates wind energy so that increased surface wind strengths are required to compensate and drive a reasonable circulation. The conventional ensemble range for the SCF parameter in GENIE-1 (forced by observed climatological wind stress) is 1 to 3 (Edwards and Marsh, 2005).

In the OSUVic model (Schmittner et al., 2010), the weak overturning circulation at $\mathrm{T} 21$ resolution discussed in Sect. 4.1.1 was, in addition to errors in the surface salinity distribution, partly attributed to low zonal wind stress in the Southern Ocean, likely due to inadequate meridional resolution (cf. Held and Phillipps, 1993). In anticipation of systematically understated Southern Ocean zonal wind stress in our T21 coupling, here we allowed SCF to vary in the range 2 to 4. 
Table 1. Ensemble varied parameters.

\begin{tabular}{llll}
\hline Parameter & Description & Range & Subjective tuning \\
\hline APM (Sv) & Atlantic-Pacific moisture flux adjustment & 0 to 0.32 & 0.2132 \\
OVD $\left(\mathrm{m}^{2} \mathrm{~s}^{-1}\right)$ & Reference diapycnal diffusivity & $2 \times 10^{-5}$ to $2 \times 10^{-4}$ & $1.583 \times 10^{-4}$ \\
OHD $\left(\mathrm{m}^{2} \mathrm{~s}^{-1}\right)$ & Isopycnal diffusivity & 500 to 5000 & 1937 \\
SCF (dimensionless) & Wind-stress scaling & 2 to 4 & 3.788 \\
ADRAG (days) & Inverse ocean drag & 0.5 to 5.0 & 2.069 \\
OP1 (dimensionless) & Power law for diapycnal diffusivity depth profile & 0.5 to 1.5 & 0.8200
\end{tabular}

\subsection{Ensemble outputs}

Thirty-seven of the 50 ensemble members successfully completed the 1000-year preindustrial spin-up simulations. These simulations exhibited a global average surface air temperature of $12.2 \pm 1.1^{\circ} \mathrm{C}(1 \sigma)$. Simulation failure was invariably associated with low frictional drag (high ADRAG); low frictional drag leads to unrealistically strong flow near the Equator and topographic features (Edwards and Marsh, 2005). Three successfully completed simulations (with inverse frictional drag 4.01, 3.21 and 3.98 days $^{-1}$ ) were excluded from the ensemble on account of unreasonably strong Pacific overturning ( $-434,-144$ and $-679 \mathrm{~Sv}$ respectively). We briefly summarise some of the characteristics of the remaining 34 simulations in terms of their response to APM, SCF and ADRAG, the three parameters that dominate the ensemble variability.

\subsubsection{APM}

The Atlantic overturning cell collapsed in all 20 simulations with APM less than $0.16 \mathrm{~Sv}$. It collapsed in only 5 of the 14 simulations with APM greater than $0.16 \mathrm{~Sv}$.

A regression of ensemble outputs suggests that the observed integrated Atlantic freshwater balance (correlation -0.92) is best reproduced for APM of approximately $0.13 \mathrm{~Sv}$, while the integrated Pacific freshwater balance (correlation +0.51$)$ is best reproduced for APM of approximately $0.26 \mathrm{~Sv}$. Values between these limits $(\sim 0.13$ to $0.26 \mathrm{~Sv})$ are therefore favoured to optimise the surface ocean inter-basin salinity distribution.

It is worth noting that these conclusions only pertain to the specific model set-up considered (i.e. the vector of all fixed parameters). We cannot rule out the possibility that alternative model parameterisations can reproduce observed salinity and circulation fields without a moisture-flux adjustment.

\subsubsection{SCF and ADRAG}

Wind-stress scaling and inverse frictional drag affect the simulations in similar ways, as expected because the role of wind-stress scaling is to compensate for frictional dissipation. Many clear relationships between these parameters and simulated outputs are apparent, for instance high values of ei- ther tend to strengthen overturning circulation and decrease sea-ice coverage in both hemispheres. It is interesting to note a strong negative correlation $(-0.61)$ between ADRAG and the integrated surface Pacific freshwater flux, opposing a positive correlation $(+0.75)$ with the integrated freshwater flux of the Indian Ocean. (Similar, though weaker, relationships exist with SCF.)

\subsection{Selection of a subjectively tuned parameter set}

Three of the 37 completed 1000-year simulations have already been ruled out for unreasonably strong Pacific overturning and a further 25 because the Atlantic overturning circulation had collapsed. Two further simulations were ruled out for unacceptably low (and still cooling) global surface air temperature $\left(<10^{\circ} \mathrm{C}\right)$ and two for an excessively evaporative Atlantic basin $(\sim 0.5 \mathrm{~Sv}$, forced by $\mathrm{APM} \sim 0.3 \mathrm{~Sv})$. The remaining five simulations were spun on for an additional 1000 years. After this spin-on, one of these simulations was ruled out under a stricter global surface air temperature constraint (requiring $>12{ }^{\circ} \mathrm{C}$ ), a further two simulations did not exhibit penetration of Antarctic Bottom Water into the Atlantic and a fourth simulation displayed a positive Pacific overturning cell that penetrated to the ocean floor north of $15^{\circ} \mathrm{N}$. The remaining simulation was clearly preferable on the basis of these simple large-scale constraints, testing for reasonable surface-ocean forcing and circulation. This subjective parameter set (see Table 1) is therefore taken as our preferred tuning.

\section{Simulated climate of the subjective tuning}

The simulated climate metrics of the subjective tuning are global average surface air temperature $12.9^{\circ} \mathrm{C}$, surface Atlantic freshwater balance $-0.35 \mathrm{~Sv}$ (including the $-0.21 \mathrm{~Sv}$ moisture flux adjustment), maximum Atlantic overturning (below $500 \mathrm{~m}$ ) $13.2 \mathrm{~Sv}$, minimum Atlantic overturning $-3.0 \mathrm{~Sv}$ and maximum Pacific overturning 6.9 Sv (restricted to high latitudes and intermediate depths, see Fig. 6). We now evaluate the climate in some detail.

Table 2 compares the subjectively tuned PLASIM-ENTS preindustrial global energy balance against a range of observationally constrained (present-day) estimates presented in 
Table 2. The global energy balance of subjectively tuned PLASIM-GENIE in the preindustrial state compared against estimates derived from the Earth Radiation Budget Experiment (ERBE; 1985-1989), when the Earth's radiation balance was in approximate equilibrium, and the Clouds and Earth's Radiant Energy System (CERES) data (2000-2004). The observational uncertainties reflect a range of analyses summarised in Trenberth et al. (2009).

\begin{tabular}{|c|c|c|c|c|c|}
\hline \multicolumn{6}{|c|}{ Solar radiation $\left(\mathrm{Wm}^{-2}\right)$} \\
\hline & $\begin{array}{r}\text { Incoming } \\
\text { TOA }\end{array}$ & $\begin{array}{l}\text { Reflected by } \\
\text { atmosphere }\end{array}$ & $\begin{array}{l}\text { Absorbed by } \\
\text { atmosphere }\end{array}$ & $\begin{array}{r}\text { Reflected by } \\
\text { surface }\end{array}$ & $\begin{array}{r}\text { Absorbed by } \\
\text { surface }\end{array}$ \\
\hline PLASIM-GENIE & 341 & 75 & 66 & 39 & 162 \\
\hline ERBE (1985-1989) & $339-343$ & $70-83$ & $64-81$ & $23-45$ & $156-169$ \\
\hline CERES (2000-2004) & $339-342$ & $69-82$ & $64-78$ & $23-45$ & $161-170$ \\
\hline \multicolumn{6}{|c|}{ Planetary radiation and heat fluxes $\left(\mathrm{Wm}^{-2}\right)$} \\
\hline & $\begin{array}{r}\text { Sensible } \\
\text { heat }\end{array}$ & $\begin{array}{r}\text { Latent } \\
\text { heat }\end{array}$ & $\begin{array}{r}\text { Back } \\
\text { radiation }\end{array}$ & $\begin{array}{r}\text { Upward surface } \\
\text { radiation }\end{array}$ & $\begin{array}{r}\text { Outgoing } \\
\text { radiation OLR }\end{array}$ \\
\hline PLASIM-GENIE & 21 & 78 & 322 & 386 & 228 \\
\hline ERBE (1985-1989) & $15-24$ & $78-85$ & $324-345$ & $390-396$ & $235-254$ \\
\hline CERES (2000-2004) & $15-19$ & $83-90$ & $324-345$ & 394-397 & $236-254$ \\
\hline
\end{tabular}

Trenberth et al. (2009). Simulated fluxes are generally within the ranges of these estimates besides reflecting the simulated cold bias that is most clearly apparent in OLR (and only partially attributable to anthropogenic forcing). Although within ranges, these data suggest that too little solar radiation is absorbed within the atmosphere and too much is reflected by the surface (likely due to the high ocean albedo; Sect. 4.1).

Table 3 compares the simulated surface ocean net moisture fluxes in each basin with the estimates of Talley (2008). The good agreement in the Atlantic is imposed by the moisture flux adjustment. We emphasise that the requirement for a flux adjustment in this parameterisation does not necessarily indicate an inherent structural weakness in the model, pending a full exploration of parameter space (cf. Williamson et al., 2015). The largest disagreement between these observations and the subjective tuning is the moisture flux differential between the Indian and Pacific oceans. The global aggregates of precipitation, evaporation and runoff are in good agreement with the observationally constrained estimates of Trenberth et al. (2007), with a modest low bias that is consistent with the simulated cold bias.

Figures 2 to 4 compare a selection of PLASIM-GENIE outputs against NCEP/NCAR reanalysis fields (Kalnay et al., 1996). In each case we compare 50-year PLASIM-GENIE averages of southern summer (DJF) and northern summer (JJA) with the corresponding long-term means (1981-2010) of the reanalysis data. The plotted outputs were chosen to highlight feedbacks that are neglected by the EMBM, viz. 3-D dynamical atmospheric transport, providing greatly improved precipitation fields and dynamic surface winds (an imposed forcing in GENIE-1), and interactive clouds (also an imposed forcing field in GENIE-1, comprising a spatiotemporal cloud albedo field and uniform OLR adjustment.)
Surface air temperature and precipitation fields are plotted in Fig. 2. The cold bias of the subjective tuning is especially apparent in the high Arctic winter. Despite the global cold bias, surface air temperatures are warm biased over the Southern Ocean, consistent with an underestimation of southern sea-ice coverage that was apparent over the entire ensemble. PLASIM precipitation fields are reasonable given our low resolution. Distinct arid regions are captured, as is the seasonal migration of the Inter-Tropical Convergence Zone and associated monsoon systems.

Figure 3 compares the surface wind fields of the subjective tuning with $10 \mathrm{~m}$ reanalysis winds. The simulated spatiotemporal distributions are in good agreement with reanalysis, although Antarctic circumpolar wind speed is somewhat understated and too northerly (cf. Schmittner et al., 2010). We note that simulated wind speeds are at the 0.983 sigma pressure level, typically $\sim 136 \mathrm{~m}$ above the surface, so that boundary layer damping is weaker than the $10 \mathrm{~m}$ reanalysis winds. Therefore, we expect greater wind speeds in the PLASIM-GENIE plots, as is generally the case. Our focus here is on the wind-stress coupling and the tuned ocean state. The 3-D atmospheric circulation is also reasonable. To illustrate, the simulated Southern/Northern Hemisphere winter zonal wind jets $\left(\sim 46 / 44 \mathrm{~ms}^{-1}, 35^{\circ} \mathrm{S} / 35^{\circ} \mathrm{N}, 150 \mathrm{mbar}\right)$ compare to reanalysis data $\left(\sim 41 / 44 \mathrm{~ms}^{-1}, 30^{\circ} \mathrm{S} / 30^{\circ} \mathrm{N}\right.$, 200 mbar).

Figure 4 compares incoming solar and thermal radiation fields with the reanalysis data. These fields are also chosen to reflect dynamics that are absent from GENIE-1, which applies prescribed planetary albedo fields and a globally uniform OLR adjustment to represent the effect of clouds on the radiation balance. The outputs plotted in Figs. 3 and 4 were chosen to focus on dynamics that are entirely absent from GENIE-1: interactive winds and interactive clouds. While 
Table 3. Simulated surface ocean moisture fluxes of the subjective tuning and observationally constrained estimates. The definition of ocean basin boundaries follows Talley (2008), viz. Atlantic and Indian oceans north of $32^{\circ} \mathrm{S}$, Pacific Ocean north of $28^{\circ} \mathrm{S}$.

\begin{tabular}{lrrrrrr}
\hline & \multicolumn{6}{c}{ Surface ocean moisture fluxes (Sv) } \\
& Atlantic/Arctic Ocean & Pacific Ocean & Indian Ocean & Southern Ocean & Total Ocean & Trenberth et al. (2007) \\
\hline Precipitation & 1.99 & 4.82 & 1.64 & 2.92 & 11.37 & 11.8 \\
Evaporation & -2.70 & -5.43 & -2.01 & -2.54 & -12.69 & -13.1 \\
Run off & 0.57 & 0.36 & 0.21 & 0.18 & 1.31 & 1.3 \\
Flux adjustment & -0.21 & 0.21 & 0.00 & 0.00 & 0.00 & \\
Net & -0.35 & -0.04 & -0.17 & 0.55 & 0.00 & \\
Talley (2008) & $-0.28 \pm 0.04$ & $0.04 \pm 0.09$ & $-0.37 \pm 0.10$ & $0.61 \pm 0.13$ & &
\end{tabular}

Talley $(2008)$ $-0.28 \pm 0.04$

$0.04 \pm 0.09 \quad-0.37 \pm 0.10$

\section{Southern summer}
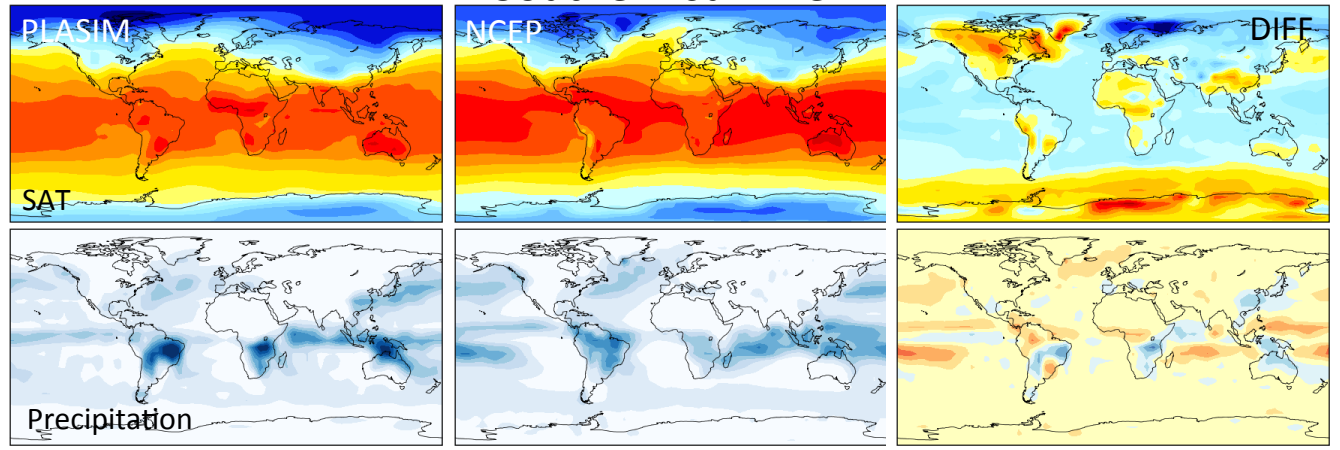

Northern summer
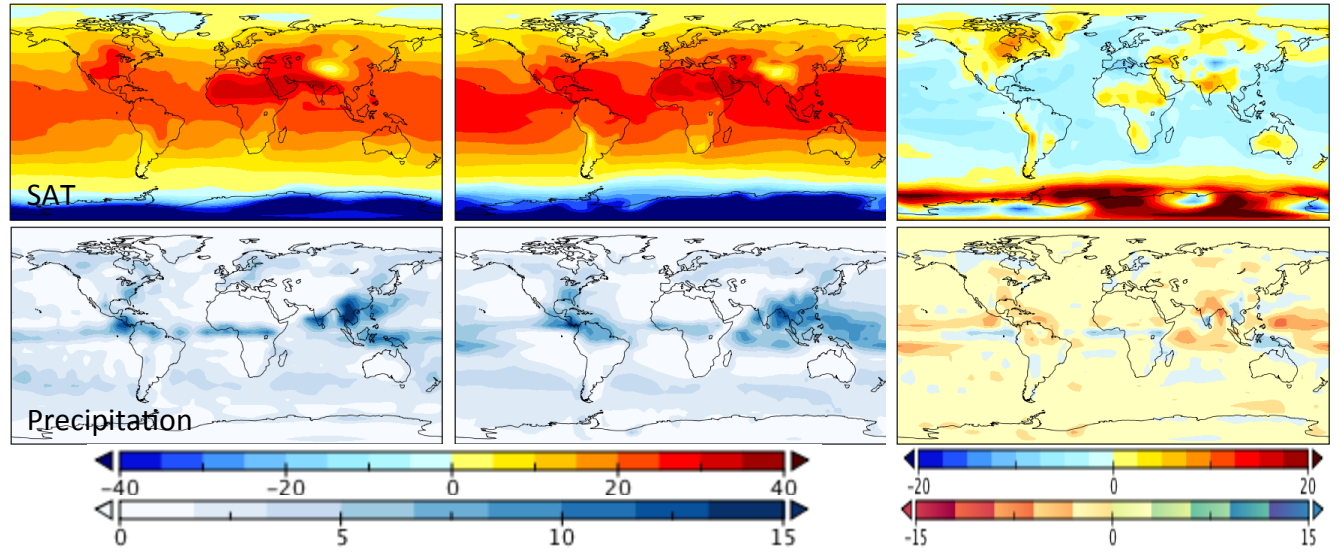

Figure 2. Seasonal surface air temperature $\left({ }^{\circ} \mathrm{C}\right)$ and precipitation $\left(\mathrm{mm} \mathrm{day}^{-1}\right)$. Left: PLASIM-GENIE 50 -year average; centre: long-term average (1981-2010) NCEP/NCAR reanalysis fields (Kalnay et al., 1996); right: difference (PLASIM-NCEP).

the inclusion of these dynamics is not expected to improve the simulated climatology (i.e. when compared to simulations that are forced with climatological fields), their inclusion represents a substantial upgrade through the capture of important Earth system feedbacks neglected in GENIE-1.

An important example of substantial improvement over the climatology of GENIE-1 is atmospheric moisture transport, previously touched upon in the context of Fig. 2. Figure 5 compares PLASIM-GENIE vegetative carbon (Fig. 5a) and GENIE-1 vegetation carbon (Fig. 5b; data reproduced from Holden et al., 2013a, Fig. 1a) and highlights various aspects of the improved moisture transport. In GENIE-1, deserts are poorly resolved (too moist) and boreal forest does not penetrate far into the continental interior of Eurasia (too dry); these are both shortcomings that arise from diffusive moisture transport (Lenton et al., 2006). Although the deserts of the Southern Hemisphere are not well resolved in either model, the larger deserts of the Northern Hemisphere are distinct in PLASIM-GENIE, while simulated boreal forest penetrates the Eurasian interior. Global terrestrial carbon storage in the subjective tuning of PLASIM-GENIE is 588 GTC (vegetation) and 1948 GTC (soil). These compare 


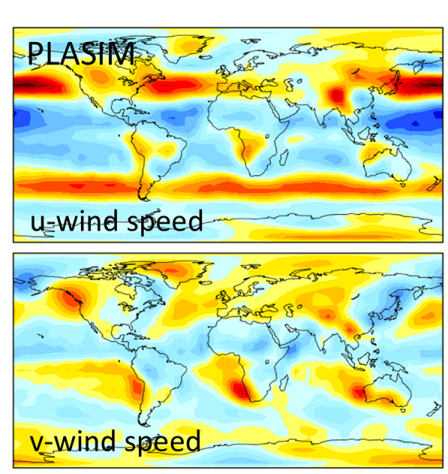

Southern summer
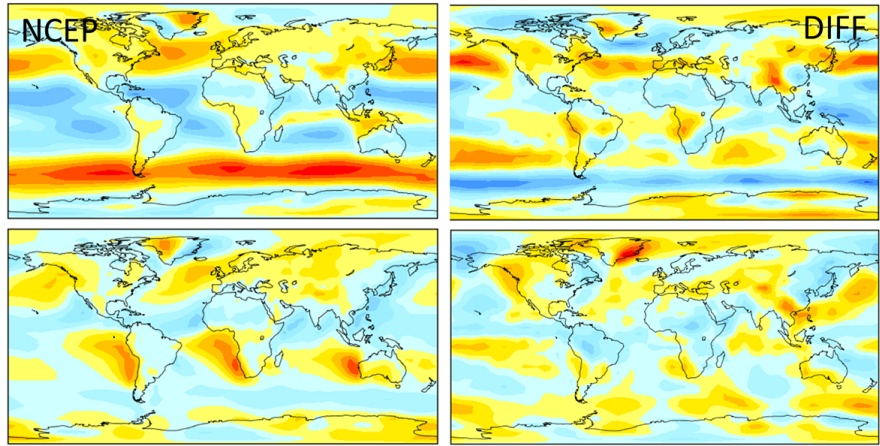

Northern summer
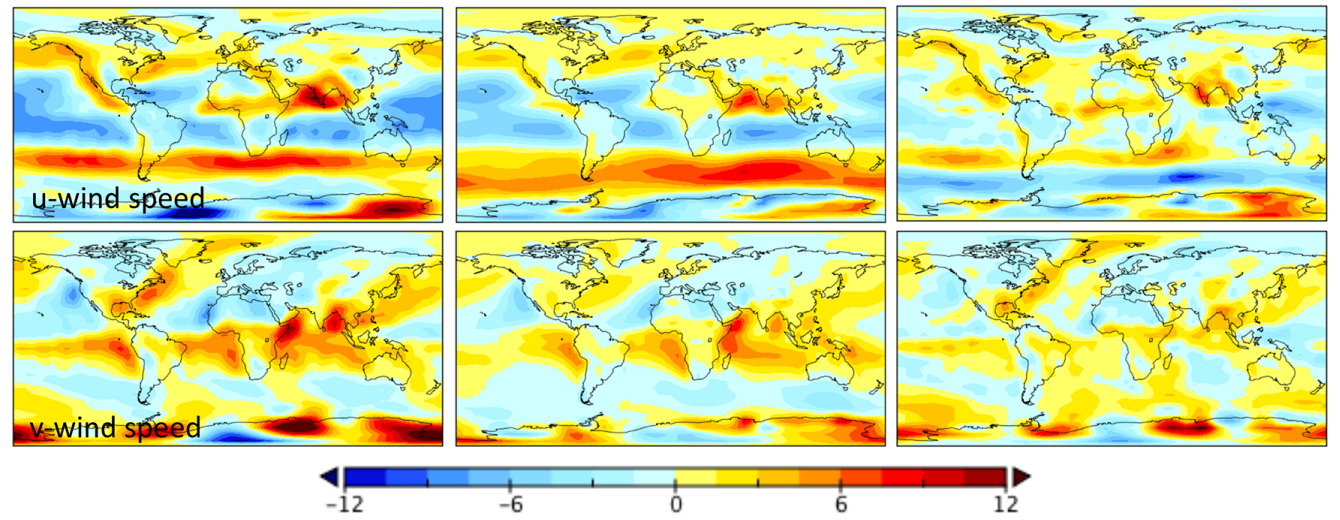

$-6$

6



12

Figure 3. Seasonal surface zonal and meridional wind speeds $\left(\mathrm{ms}^{-1}\right)$. Left: PLASIM-GENIE 50-year average. Centre: long-term average (1981-2010) NCEP/NCAR reanalysis fields (Kalnay et al., 1996). Right: difference (PLASIM-NCEP).

to 491-574 and 1367-1416 GTC respectively, in GENIE-1 (Lenton et al., 2006). The significantly higher soil carbon values in PLASIM-GENIE primarily reflect the increased area of Eurasian boreal forest, where soil carbon is respired slowly due to the low temperatures. The global terrestrial carbon pools are consistent with ranges of 460-660 GTC (vegetation) and 850-2400 GTC (soil) derived from a range of observational and modelling studies and summarised in Bondeau et al. (2007).

The framework of climate analysis by Budyko (1974) is based on the climate mean dryness ratio $D$ or aridity index (mean energy supply or net radiation $N$ to mean water supply or precipitation $P$ ). It provides quantitative geobotanically relevant thresholds for land surface climate regimes that are related to vegetation structures (Fig. 5 c): tundra $-D<1 / 3$ and forests $-1 / 3<D<1$ are energy limited $(D<1)$ because available energy $N$ is low, so that runoff exceeds evaporation for given precipitation, $E \sim N$. Steppe and savanna $-1<D<2$, semi-desert $-2<D<3$ and desert $-3>D$ are water-limited climates $(D>1)$, where the available energy is so high that water supplied by precipitation evaporates, which then exceeds runoff, $E-P$. This analysis highlights the Tibetan Plateau and North American Arctic climates and demonstrates consistency with the simulated vegetation carbon (Fig. 5a). The similarity with ERA-interim- based analysis (Cai et al., 2014, Fig. 1a) is notable. Similarly, a bucket model interpretation of the land surface climate (Fraedrich et al., 2016) is possible using the soil moisture fraction, $S=s / s^{*}=E / N$, and is plotted in Fig. 5d.

Sea-ice distributions (not illustrated) exhibit a systematic bias towards low southern sea-ice area across the ensemble, with an annual average of 2.5 million $\mathrm{km}^{2}$ in the subjective tuning; this compares to observational estimates of 11.5 million $\mathrm{km}^{2}$ (Cavalieri et al., 2003). Surface air temperature over the Southern Ocean is warm biased with respect to the reanalysis data, despite a modest cold bias in the global temperature (Fig. 2). While this may in part be a consequence of reduced sea-ice (through the albedo feedback), the continued presence of the warm bias in southern summer suggests the possibility that the bias arises in the atmosphere. The decision to control the global temperature with acllwr (Sect. 4.1) preferentially warms cloudy regions and may have contributed. Indeed, simulated downward thermal radiation exhibits a significant positive bias over the Southern Ocean (Fig. 4). A thorough investigation of the source of this bias is beyond the scope of this study, requiring consideration of uncertainties in atmospheric and ocean energy transport, and in solar and thermal radiative transfer, considering clouds, water vapour and surface processes. 


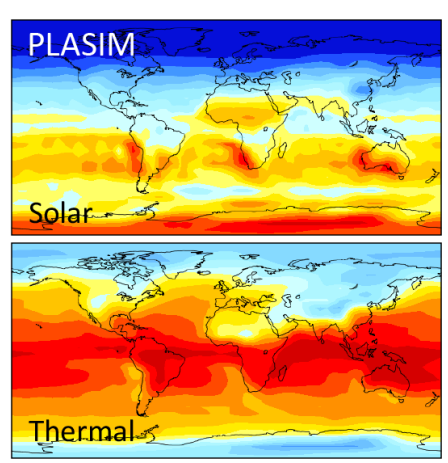

\section{Southern summer}
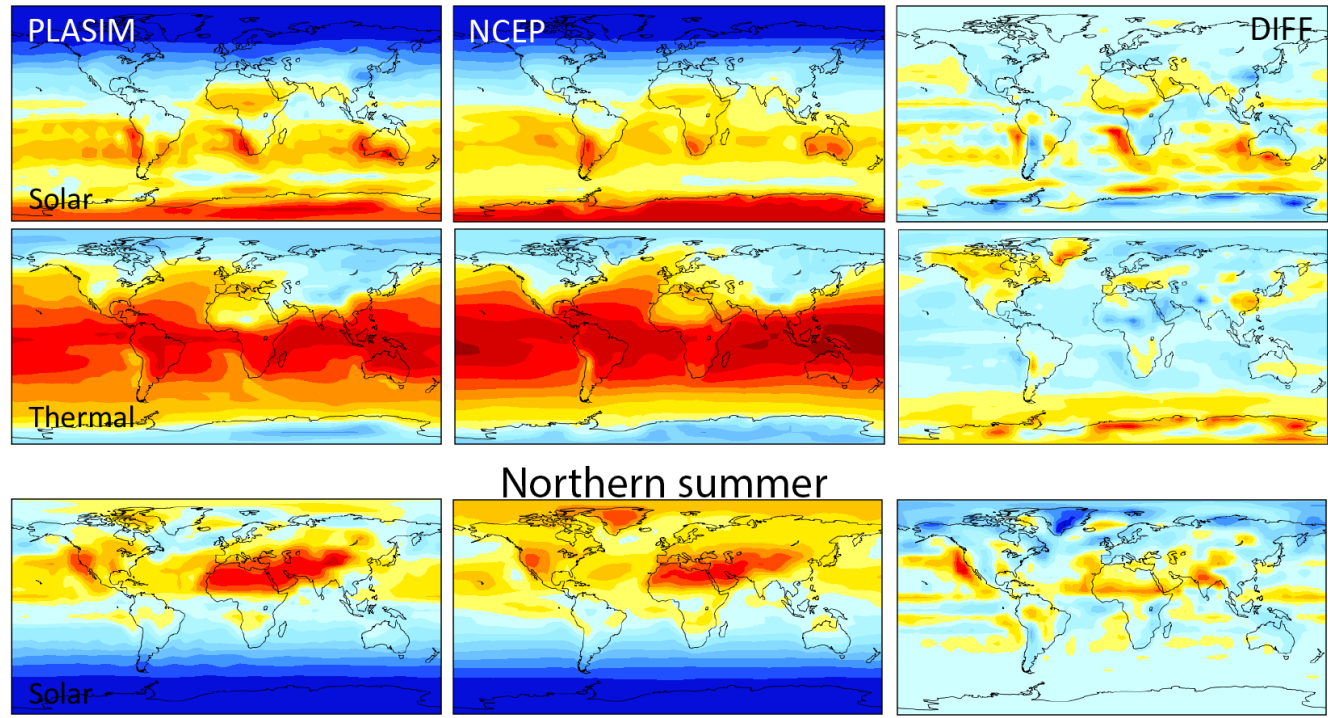

\section{Northern summer}
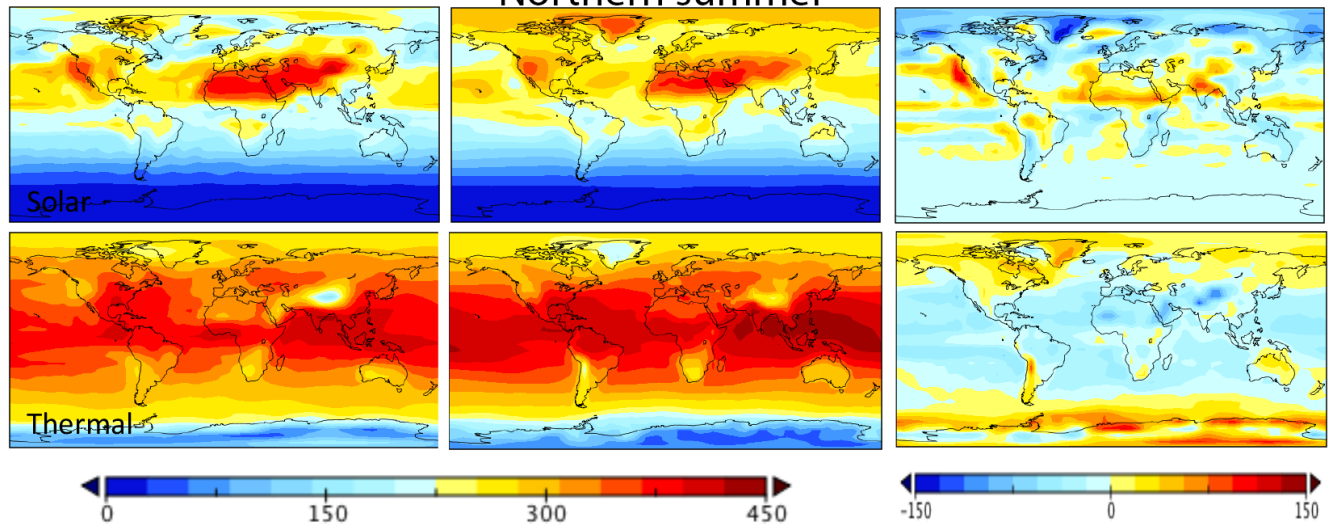

150
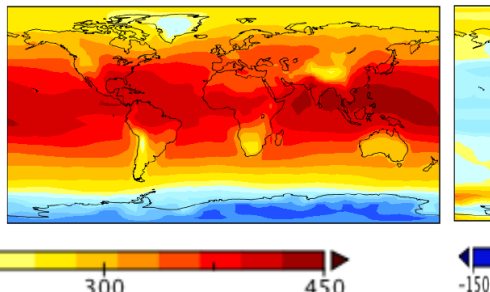

$-150$

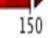

Figure 4. Seasonal incoming surface solar and thermal radiation $\left(\mathrm{Wm}^{-2}\right)$. Left: PLASIM-GENIE 50-year averages; centre: long-term average (1981-2010) NCEP/NCAR reanalysis fields (Kalnay et al., 1996); right: difference (PLASIM-NCEP).
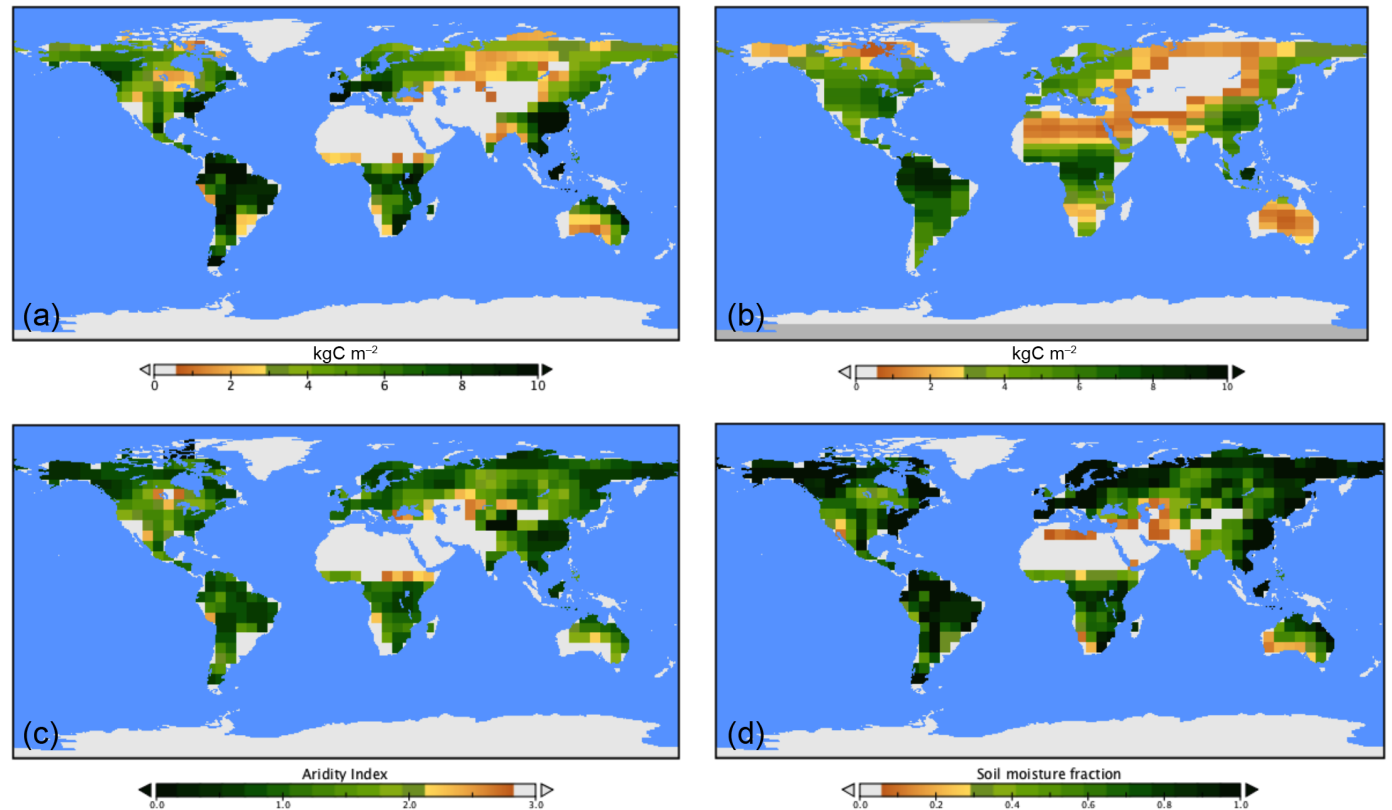

Figure 5. Land surface. (a) ENTS vegetation carbon density from PLASIM-GENIE, (b) ENTS vegetation carbon density from GENIE-1 (Holden et al., 2013a), (c) Budyko aridity index $N / P$ and (d) soil moisture fraction $E / N$. 

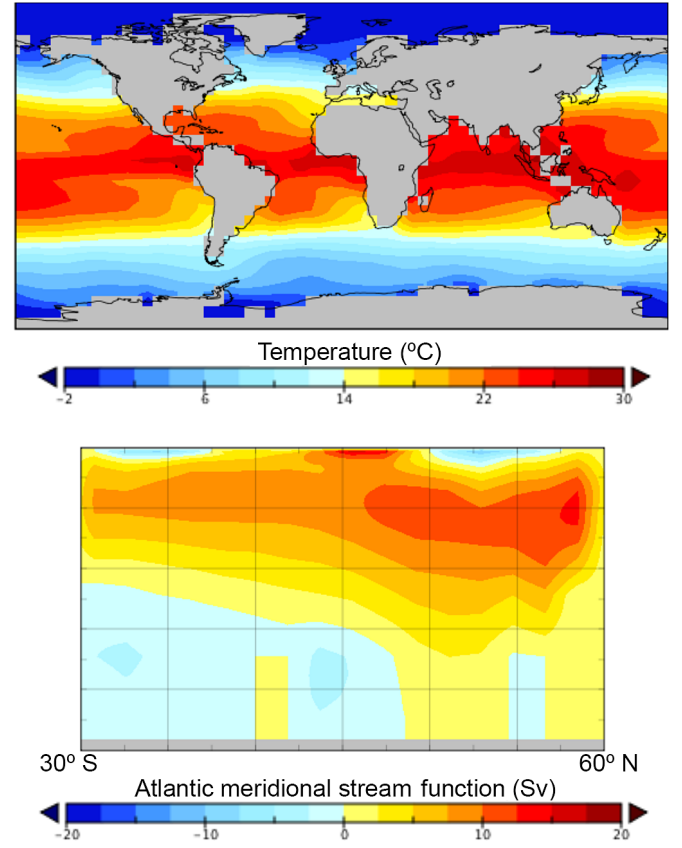
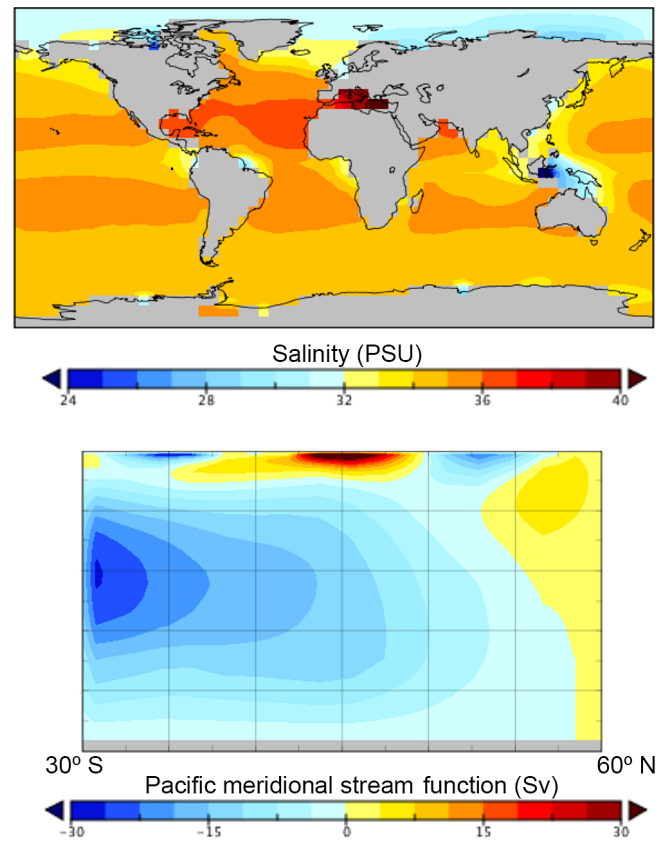

Figure 6. Ocean. Upper panels: PLASIM-GENIE simulated surface ocean temperature and salinity; lower panels: PLASIM-GENIE simulated Atlantic and Pacific meridional stream functions.

Figure 6 illustrates aspects of the simulated ocean state that directly reflect the constraints imposed upon the subjective parameter set and require little further discussion. It is worth emphasising again that the simulation of realistic salinity fields and ocean circulation required an AtlanticPacific moisture flux adjustment in this parameterisation (Sects. 4.1.1 and 4.2.1).

The upper panel of Fig. 7 plots the PLASIMGENIE barotropic stream function. Simulated gyre strengths are $26 \mathrm{~Sv} /-30 \mathrm{~Sv}$ North/South Atlantic, $54 \mathrm{~Sv} /-56 \mathrm{~Sv}$ North/South Pacific and $4 \mathrm{~Sv} /-36 \mathrm{~Sv}$ North/South Indian Ocean. For comparison, the gyre strengths of climatological wind-forced $64 \times 32$ GENIE- 1 were simulated at $\sim 20 \mathrm{~Sv} /-20 \mathrm{~Sv}$ North/South Atlantic, $\sim 30 \mathrm{~Sv} /-30 \mathrm{~Sv}$ North/South Pacific and $\sim 3 \mathrm{~Sv} /-40 \mathrm{~Sv}$ North/South Indian Ocean (see Fig. 19d, Marsh et al., 2011). Stronger gyres in the PLASIM-GENIE simulation compared to the GENIE-1 simulation are likely to be related to larger values of wind-stress scaling in the PLASIM-GENIE case, given that the simulated wind forcing is relatively close to climatology. The observed Gulf Stream strength is estimated at $32 \mathrm{~Sv}$, while simulated strengths ranged from 13 to $48 \mathrm{~Sv}$ in the multi-model comparison of Balan-Sarojini et al. (2011). The Antarctic Circumpolar Current (ACC) is weaker in PLASIM-GENIE (32 Sv) than GENIE-1 (47 Sv), presumably reflecting the weak simulated Southern Ocean zonal winds (see Fig. 3). Note that both models significantly understate the ACC strength compared to observations of $140 \pm 6$ Sv (Ganachaud and Wunsch, 2000).
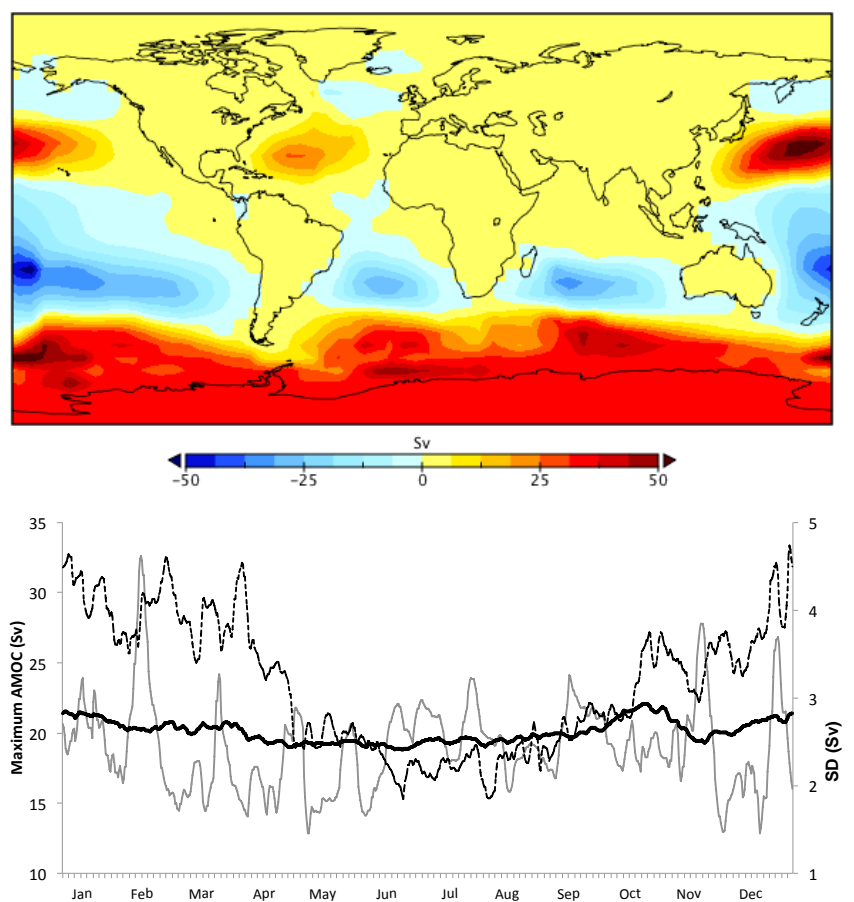

Figure 7. Upper panel: PLASIM-GENIE barotropic stream function. Lower panel: Wind-driven AMOC variability: solid black 100year mean, dashed black 100-year standard deviation, solid grey arbitrary year (year 1 of a 100-year spin-on simulation). 
The lower panel of Fig. 7 illustrates high-frequency AMOC variability driven by atmospheric dynamics, behaviour that is absent from GENIE-1 (Balan-Sarojini et al., 2011). The maximum Atlantic overturning circulation is plotted through an arbitrary year (first year of a spin-on simulation), together with the 100-year mean and standard deviation.

\section{Summary and conclusions}

We have presented a new intermediate complexity AOGCM PLASIM-GENIE, which reproduces the main features of the climate system well and represents a substantial upgrade to GENIE-1 through the representation of important atmospheric dynamical feedbacks that are absent in an EMBM. PLASIM-GENIE has been developed to join the limited number of intermediate complexity models with primitiveequation atmospheric dynamics. It supersedes an earlier coupling with the IGCM (GENIE-2), which was contaminated with spurious numerically generated features, limiting its usefulness.

The simple subjective tuning approach applied here considered only six ocean parameters, seeking a reasonable ocean circulation when coupled to PLASIM-ENTS (both PLASIM and ENTS have previously been tuned with climatological forcing). This limited tuning approach required approximately 2 CPU years, demanding but readily tractable, representing approximately 2 weeks of computation on 50 cluster nodes.

A reasonable ocean circulation state and salinity distribution required the application of an Atlantic-Pacific moisture flux adjustment. We do not rule out the possibility that a full investigation of PLASIM-GENIE parametric uncertainty could generate a plausible ocean circulation without a flux adjustment, and may additionally resolve the understated southern sea ice. However, a comprehensive tuning will demand the application of more complex statistical approaches designed to deal with computationally demanding simulators. For instance, the use of emulators to inform a sequential ensemble design process has been demonstrated to yield $\mathrm{a} \sim 100$-fold reduction in computational demand (Holden et al., 2016).

\section{Code availability}

The code base is stored on a password-protected SVN server https://svn.ggy.bris.ac.uk/subversion/genie/branches/ PLASIM_coupling

Contact the authors for the password. The model is under continuous development; see SVN revision 9765 for traceability.

We recommend setting up a root directory (e.g. PLASIMGENIE) containing the subdirectories genie_output and ge- nie, the latter containing the directory structure downloaded from the SVN repository.

In addition to the source code, PLASIM-GENIE makes use of several applications and packages. You must have the following list of prerequisites installed on your computer before you can run the model: Python, Perl, GNU make, the BASH shell, a $\mathrm{C}++$ compiler, a Fortran compiler that supports Fortran90, and NetCDF libraries (compiled on the same computer using the same compilers that you will use to compile PLASIM-GENIE).

Before you compile the model you must provide information about (i) where you have installed the source code, (ii) which compilers you are using and (iii) the location of the netCDF libraries that you have created; this is achieved by editing the files user.mak and user.sh in the directory geniemain. Comments in those files explain which lines need to be edited.

A configuration file contains all the information required to specify a simulation. The code base includes a configuration file to perform a 1000-year spin-up with the subjective parameter set "genie/geniemain/configs/pl_go_gs_GMD.xml". This configuration file has been fully commented for traceability to this model description paper and to explain how to generalise to other model realisations. To run this simulation, enter the genie/genie-main directory and type:

make cleanall

./genie.job -f configs/pl_go_gs_GMD.xml

The outputs of this simulation will be directed to genie_output/GMD_subjective.

Acknowledgements. The work of Kirk, Lunkeit and Zhu was supported through the Cluster of Excellence "CliSAP" (EXC177), Universität Hamburg, funded through the German Science Foundation (DFG).

Edited by: J. Hargreaves

Reviewed by: two anonymous referees

\section{References}

Annan, J. D., Lunt, D. J., Hargreaves, J. C., and Valdes, P. J.: Parameter estimation in an atmospheric GCM using the Ensemble Kalman Filter, Nonlin. Processes Geophys., 12, 363-371, doi:10.5194/npg-12-363-2005, 2005.

Balan Sarojini, B., Gregory, J. M., Tailleux, R., Bigg, G. R., Blaker, A. T., Cameron, D. R., Edwards, N. R., Megann, A. P., Shaffrey, L. C., and Sinha, B.: High frequency variability of the Atlantic meridional overturning circulation, Ocean Sci., 7, 471486, doi:10.5194/os-7-471-2011, 2011.

Betts, A. K. and Miller, M. J.: A new convective adjustment scheme. Part II: Single column tests using GATE wave, BOMEX, ATEX and arctic air-mass data sets, Q. J. Roy. Meteor. Soc., 112, 693709, 1986. 
Bondeau, A., Smith, P. C., Zaehle, S., Schaphoff, S., Lucht, W., Cramer, W., Gerten, D., Lotze-Campen, H., Müller, C., Reichstein, M., and Smith, B.: Modelling the role of agriculture for the 20th century global terrestrial carbon balance, Glob. Change Biol., 13, 679-706, doi:10.1111/j.13652486.2006.01305.x, 2007.

Budyko, M.: Climate and Life, Vol. 18, Academic Press, 508 pp., 1974.

Cai, D., Fraedrich, K., Sielmann, F., Guan, Y., Guo, S., Zhang, L., and Zhu, X.: Climate and vegetation: an ERA-interim and GIMMS NVDI analysis, J. Climate, 27, 5111-5118, doi:10.1175/JCLI-D-13-00674.1, 2014.

Cavalieri, D. J., Parkinson, C. L., and Yinnikov, K. Y.: 30year satellite record reveals contrasting Arctic and Antarctic decadal sea-ice variability, Geophys. Res. Lett., 30, 1970, doi:10.1029/2003GL018031, 2003.

Dahms, E., Borth, H., Lunkeit, F., and Fraedrich, K.: ITCZ splitting and the influence of large-scale eddy fields on the Tropical mean state, J. Meteorol. Soc. Jpn., 89, 399-411, doi:10.2151/jmsj.2011-501, 2011.

de Forster, P. M., Blackburn, M., Glover, R., and Shine, K. P.: An examination of climate sensitivity for idealised climate change experiments in an intermediate general circulation model, Clim. Dynam., 16, 833-849, doi:10.1007/s003820000083, 2000.

Edwards, N. R. and Marsh, R.: Uncertainties due to transportparameter sensitivity in an efficient 3-D ocean-climate model, Clim. Dynam., 24, 415-433, doi:10.1007/s00382-004-0508-8, 2005.

Edwards, N. R., Willmott, A. J., and Killworth, P. D.: On the role of topography and wind stress on the stability of the thermohaline circulation, J. Phys. Oceanogr., 28, 756-778, 1998.

Fanning, A. F. and Weaver, A. J.: An atmospheric energy-moisture balance model: climatology, interpentadal climate change, and coupling to an ocean general circulation model, J. Geophys. Res., 101, 15111-15128, doi:10.1029/96JD01017, 1996.

Fraedrich, K.: A suite of user-friendly climate models: Hysteresis experiments, Eur. Phys. J. Plus, 127, 53, doi:10.1140/epjp/i201212053-7, 2012.

Fraedrich, K. and Lunkeit, F.: Diagnosing the entropy budget of a climate model, Tellus A, 60, 921-931, doi:10.1111/j.16000870.2008.00338.x, 2008.

Fraedrich, K., Kirk, E., Luksch, U., and Lunkeit, F.: The portable university model of the atmosphere (PUMA): Storm track dynamics and low-frequency variability, Meteorol. Z., 14, 735-745, doi:10.1127/0941-2948/2005/0074, 2005.

Fraedrich, K., Sielmann, F., Cai, D., and Zhu, X.: Climate dynamics on watershed scale: along the rainfall-runoff chain, in: The Fluid Dynamics of Climate, International Centre for Mechanical Sciences (CISM), Springer Verlag, 183-209, 2016.

Frierson, D. M. W., Held, I. M., and Zurita-Gotor, P.: A grayradiation aquaplanet moist GCM. Part I. Static stability and eddy scale, J. Atmos. Sci., 63, 2548-2566, 2006

Ganachaud A. and Wunsch C.: Improved estimates of global ocean circulation, heat transport and mixing from hydrographic data, Nature, 408, 453-457, doi:10.1038/35044048, 2000.

Held, I. M. and Phillipps, P. J.: Sensitivity of the eddy momentum flux to meridional resolution in atmospheric GCMs, J. Climate, 6, 499-507, 1995.
Hibler, W. D.: Dynamic thermodynamic sea ice model, J. Phys. Oceanogr., 9, 815-846, 1979.

Holden, P. B. and Edwards, N. R.: Dimensionally reduced emulation of an AOGCM for application to integrated assessment modelling, Geophys. Res. Lett., 37, L21707, doi:10.1029/2010GL045137, 2010.

Holden, P. B., Edwards, N. R., Oliver, K. I. C, Lenton, T. M., and Wilkinson, R. D.: A probabilistic calibration of climate sensitivity and terrestrial carbon storage in GENIE-1, Clim. Dynam., 35, 785-908, doi:10.1007/s00382-009-0630-8, 2010.

Holden, P. B., Edwards, N. R., Gerten, D., and Schaphoff, S.: A model-based constraint on $\mathrm{CO}_{2}$ fertilisation, Biogeosciences, 10, 339-355, doi:10.5194/bg-10-339-2013, $2013 \mathrm{a}$.

Holden, P. B., Edwards, N. R., Müller, S. A., Oliver, K. I. C., Death, R. M., and Ridgwell, A.: Controls on the spatial distribution of oceanic $\delta^{13} \mathrm{C}_{\text {DIC }}$, Biogeosciences, 10, 1815-1833, doi:10.5194/bg-10-1815-2013, 2013b.

Holden, P. B., Edwards, N. R., Garthwaite, P. H., Fraedrich, K., Lunkeit, F., Kirk, E., Labriet, M., Kanudia, A., and Babonneau, F.: PLASIM-ENTSem v1.0: a spatio-temporal emulator of future climate change for impacts assessment, Geosci. Model Dev., 7, 433-451, doi:10.5194/gmd-7-433-2014, 2014.

Holden, P. B., Edwards, N. R., Hensman, J., and Wilkinson, R. D.: ABC for climate: dealing with expensive simulators, in: Approximate Bayesian Computation: Likelihood-Free Methods for Complex Models, edited by: Sisson, S. A., Fan, Y., and Beaumont, M., Chapman and Hall, in press, 2016.

Hoskins, B. J. and Simmons, A. J.: A multi-layer spectral model and the semi-implicit method, Q. J. Roy. Meteorol. Soc., 101, 637-655, doi:10.1002/qj.49710142918, 1975.

Kalnay, E., Kanamitsu, M., Kistler, R., Collins, W., Deaven, D., Gandin, L., Iredell, M., Saha, S., White, G., Woollen, J., Zhu, Y., Leetmaa, A., Reynolds, R., Chelliah, M., Ebisuzaki, W., Higgins, W., Janowiak, J., Mo, K. C., Ropelewski, C., Wang, J., Jenne, R., and Joseph, D.: The NCEP/NCAR 40-Year Reanalysis Project, B. Am. Meteorol. Soc., 77, 437-471, 1996.

Kleidon, A., Fraedrich, K., and Low, C.: Multiple steady-states in the terrestrial atmosphere-biosphere system: a result of a discrete vegetation classification?, Biogeosciences, 4, 707-714, doi:10.5194/bg-4-707-2007, 2007.

Kuo, H. L.: On formation and intensification of tropical cyclones through latent heat release by cumulus convection. J. Atmos. Sci., 22, 40-63, 1965.

Kuo, H. L.: Further studies of the parameterization of the influence of cumulus convection on large-scale flow, J. Atmos. Sci., 31, 1232-1240, 1974.

Labriet, M., Joshi, S. R., Vielle, M., Holden, P. B., Edwards, N. R., Kanudia, A., Loulou, R., and Babonneau, F.: Worldwide impacts of climate change on energy for heating and cooling, Mitigation and Adaptation Strategies for Global Change, 20, 1111-1136, doi:10.1007/s11027-013-9522-7, 2015.

Lenton, T. M., Williamson, M. S., Edwards, N. R., Marsh, R., Price, A. R., Ridgwell, A. J., Shepherd, J. G., Cox, S. J., and The GENIE team: Millennial timescale carbon cycle and climate change in an Efficient Earth system model, Clim. Dynam., 26, 687-711, doi:10.1007/s00382-006-0109-9, 2006.

Lenton, T. M., Aksenov, Y., Cox, S. J., Hargreaves, J. C., Marsh, R., Price, A. R., Lunt, D. J., Annan, J. D., Cooper-Chadwick, T., Edwards, N. R., S. Goswami, S., Livina, V. N., P. J. Valdes, 
P. J., Yool, A., Harris, P. P., Jiao, Z., Payne, A. J., Rutt, I. C., Shepherd, J. G. Williams, G., and Williamson, M. S.: Effects of atmospheric dynamics and ocean resolution on bistability of the thermohaline circulation examined using the Grid Enabled Integrated Earth system modelling (GENIE) framework, Clim. Dynam., 29, 591-613, doi:10.1007/s00382-007-0254-9, 2007.

Lunkeit, F., Böttinger, M., Fraedrich, K., Jansen, H., Kirk, E., Kleidon, A., and Luksch U.: Planet Simulator Reference Manual Version 15.0, available at: http://epic.awi.de/29588/1/Lun2007d.pdf (last access: 7 September 2016), 2007.

Marsh, R., Müller, S. A., Yool, A., and Edwards, N. R.: Incorporation of the C-GOLDSTEIN efficient climate model into the GENIE framework: "eb_go_gs" configurations of GENIE, Geosci. Model Dev., 4, 957-992, doi:10.5194/gmd-4-957-2011, 2011.

Matthews, H. D. and Caldeira, K.: Transient climate-carbon simulations of planetary geoengineering, Proc. Natl. Acad. Sci. USA, 104, 9949-9954, doi:10.1073/pnas.0700419104, 2007.

Mercure, J.-F., Pollitt, H., Chewpreecha, U., Salas, P., Foley, A. M., Holden, P. B., and Edwards, N. R.: The dynamics of technology diffusion and the impacts of climate policy instruments in the decarbonisation of the global electricity sector, Energ. Policy, 73, 686-700, doi:10.1016/j.enpol.2014.06.029, 2014.

Micheels, A. and Montenari, M.: A snowball Earth versus a slush-ball Earth: Results from Neoproterozoic climate modeling sensitivity experiments, Geosphere, 4, 401-410, doi:10.1130/GES00098.1, 2008.

Molteni, F.: Atmospheric simulations using a GCM with simplified physical parameterizations. I: Model climatology and variability in multi-decadal experiments, Clim. Dynam., 20, 175-191, 2003.

Oliver, K. I. C. and Edwards, N. R.: Location of potential energy sources and the export of dense water from the Atlantic Ocean, Geophys. Res. Lett., 35, L22604, doi:10.1029/2008GL035537, 2008.

Oort, A. H.: Global atmospheric circulation statistics, 1958-1973, NOAA Prof Pap 14, 1983.

Pacanowski, R.: MOM 2 Documentation User's Guide and Reference Manual, GFDL Ocean Group Technical Report. NOAA, GFDL. Princeton, 232 pp., 1995.

Plattner, G.-K., Knutti, R., Joos, F., Stocker, T. F., von Bloh, W., Brovkin, V., Cameron, D., Driesschaert, E., Dutkiewicz, S., Eby, M., Edwards, N. R., Fichefet, T., Hargreaves, J. C., Jones, C. D., Loutre, M. F., Matthews, H. D., Mouchet, A., Mueller, S. A., Nawrath, S., Price, A., Sokolov, A., Strassmann, K. M., and Weaver, A. J.: 2008 Long-term climate commitments projected with climate - carbon cycle models, J. Climate, 21, 2721-2751, doi:10.1175/2007JCLI1905.1, 2008.

Roscher, M., Stordal, F., and Svenson, H.: The effect of global warming and global cooling on the distribution of the latest Permian climate zones, Palaeogeogr. Palaeocl., 309, 186-200, doi:10.1016/j.palaeo.2011.05.042, 2011.
Schmittner, A., Silva, T. A. M., Fraedrich, K., Kirk, E., and Lunkeit, F.: Effects of mountains and ice sheets on global ocean circulation, J. Climate, 24, 2814-2829, doi:10.1175/2010JCLI3982.1, 2010.

Semtner, A. J.: Model for thermodynamic growth of sea ice in numerical investigations of climate, J. Phys. Oceanogr., 6, 379-389, 1976.

Severijns, C. A. and Hazeleger, W.: The efficient global primitive equation climate model SPEEDO V2.0, Geosci. Model Dev., 3, 105-122, doi:10.5194/gmd-3-105-2010, 2010.

Slingo, A. and Slingo, J. M.: Response of the National Center for Atmospheric Research community climate model to improvements in the representation of clouds, J. Geophys. Res., 96, 341357, 1991.

Talley, L. D.: Freshwater transport estimates and the global overturning circulation: Shallow, deep and throughflow components, Progr. Oceanogr., 78, 257-303, doi:10.1016/j.pocean.2008.05.001, 2008.

Trenberth, K. E., Smith, L., Qian, T., Dai, A., and Fasullo, J.: Estimates of the global water budget and its annual cycle using observational and model data, J. Hydrometeorol Special Section, 8 , 758-769, doi:10.1175/JHM600.1, 2007.

Trenberth, K. E., Fasullo, J. T., and Kiehl, J.: Earth's global energy budget, B. Am. Meteorol. Soc., 90, 311-323, doi:10.1175/2008BAMS2634.1, 2009.

Williams, J. H. T., Smith, R. S., Valdes, P. J., Booth, B. B. B., and Osprey, A.: Optimising the FAMOUS climate model: inclusion of global carbon cycling, Geosci. Model Dev., 6, 141-160, doi:10.5194/gmd-6-141-2013, 2013.

Williamson, D., Blaker, A. T., Hampton, C., and Salter, J.: Identifying and removing structural biases in climate models with history matching, Clim. Dynam., 45, 1299-1324, doi:10.1007/s00382014-2378-z, 2015.

Williamson, M. S., Lenton, T. M., Shepherd, J. G., and Edwards, N. R.: An efficient numerical terrestrial scheme (ENTS) for Earth system modelling, Ecol. Model., 198, 362-374, doi:10.1016/j.ecolmodel.2006.05.027, 2006.

Zickfeld, K., Eby, M., Weaver, A. J., Crespin, E., Fichefet, T., Goosse, H., Philippon-Berthier, G., Edwards, N. R., Holden, P. B., Eliseev, A. V., Mokhov, I. I., Feulner, G., Kienert, H., Perrette, M., Schneider von Deimling, T., Forest, C. E., Joos, F., Spahni, R., Steinacher, M., Kawamiya, M., Tachiiri, K., Kicklighter, D., Monier, E., Schlosser, A., Sokolov, A. P., Matsumoto, K., Tokos, K., Olsen, S. M., Pedersen, J. O. P., Shaffer, G., Ridgwell, A., Zeng, N., and Zhao, F.: Long-term climate change commitment and reversibility, J. Climate, 26, 5782-5809, doi:10.1175/JCLID-12-00584.1, 2013. 